\title{
The surgical management of massive intraoperative and postoperative suprachoroidal hemorrhage - anatomic and functional outcomes
}

\author{
O tratamento cirúrgico da hemorragia supracoroidea massiva intraoperatória e pós-operatória: \\ resultados anatômicos e funcionais
}

Fabio Lavinsky ${ }^{1,2}$, Joseph Moisseiev ${ }^{1}$, Hani LeVkovitch-Verbin ${ }^{1}$

\begin{abstract}
Purpose: To describe the clinical characteristics, management and treatment outcomes of patients with post-surgical suprachoroidal hemorrhage $(\mathrm{SCH})$.

Methods: A retrospective cross-sectional study was conducted, in which the medical records of 9 consecutive patients with SCH admitted to the Goldschleger Eye Institute were reviewed.

Results: The mean age was 74 years (range 61-84) and the mean follow-up time was $38.3 \pm 0.1$ months (range 4-87 months). Four cases were associated with glaucoma surgeries (2 trabeculectomies and 2 Ahmed valve implantations), 3 cases with cataract surgery and 2 cases with pars plana vitrectomy. The diagnosis of $\mathrm{SCH}$ was ranging from intra-operative to 8 days following the primary procedure. Most patients underwent posterior sclerotomies and drainage alone or combined with pars plana vitrectomy in a mean timing of intervention of $11 \pm 4$ days. At one month of follow-up the visual acuity improved in 7 eyes and remained stable in 2 , compared to the VA prior to the drainage operation. The mean VA improved from 2.03 to 1.285 logMAR units at 1 month following the drainage procedure $(p=0.003)$. Conclusions: $\mathrm{SCH}$ still remains a challenging complication of many ophthalmological procedures. The current surgical management may improve visual acuity though the general prognosis is still poor.
\end{abstract}

Keywords: Choroid hemorrhage/complications; Cataract extraction; Glaucoma/ surgery; Vitrectomy; Ophthalmologic surgical procedures/complications

\begin{abstract}
RESUMO
Objetivos: Descrever as características clínicas, manejo e desfechos do tratamento de pacientes com hemorragia supracoroidea pós-operatória.

Métodos: Um estudo transversal foi realizado. Neste foram revisados os prontuários médicos de nove pacientes consecutivos com hemorragia supracoroidea que foram admitidos para internação no Serviço de Oftalmologia do Goldschleger Eye Institute. Resultados: A média de idade foi 74 anos (61-84) e o tempo médio de seguimento foi 38,3 $\pm 0,1$ meses (4-87 meses). Quatro casos foram associados com cirurgias de glaucoma (2 trabeculectomias e 2 implantes de válvula de Ahmed), 3 casos com cirurgia de catarata e 2 casos com vitrectomia. O diagnóstico de hemorragia supracoroidea foi de intraoperatório até 8 dias após o procedimento primário. A maioria dos pacientes se submeteu a esclerectomia posterior e drenagem com ou sem vitrectomia via pars plana combinada. A média do tempo de intervenção foi $11 \pm 4$ dias. Após um mês de seguimento a acuidade visual melhorou em 7 ol hos e se manteve estável em 2, comparando com a acuidade visual prévia a cirurgia de drenagem. A acuidade visual media melhorou de 2,03 para 1,285 logMAR após 1 mês de seguimento depois da drenagem por esclerectomia posterior $(p=0,003)$.

Conclusões: Hemorragia supracoroidea ainda é uma complicação desafiadora de muitos procedimentos oftalmológicos. O manejo cirúrgico atual pode melhorar a acuidade visual apesar de o prognostico desta afecção ser ainda reservado.
\end{abstract}

Descritores: Hemorragia da coroide/complicações; Extração decatarata; Glaucoma/ cirurgia; Vitrectomia; Procedimentos cirúrgicos oftalmológicos/cirurgia

\section{INTRODUCTION}

Appositional suprachoroidal hemorrhage (SCH) ("expulsive hemorrhage") is considered as one of the most devastating complication of intraocular surgery. Most studies report poor prognosis with low visual acuity at follow up ${ }^{(1-3)}$. SCH has been reported to occur in the setting of all types of intraocular procedures, including cataract extraction $^{(4-7)}$, penetrating keratoplasty ${ }^{(8-10)}$, glaucoma filtering surgery ${ }^{(10-12)}$, and vitreoretinal surgery ${ }^{(13-15)}$. The incidence of expulsive $\mathrm{SCH}$ during glaucoma filtering surgery has been reported to be approximately $0.15 \%{ }^{(10)}$ The hypotonous eye may be more susceptible to episcleral venous pressure fluctuations induced by post-operative Valsalva maneuvers and therefore, be more vulnerable to rupture of cilliary arteries $^{(1,16)}$. Myopia was also described as a potential risk factor ${ }^{(1)}$.

The systemic risk factors described to be associated with $\mathrm{SCH}$ such as advanced age, systemic hypertension (HTN), and arteriosclerosis are presumably related to increased sclerosis and fragility of the choroidal vessels $s^{(1,17,18)}$. Other risk factors implicated in these patients are blood dyscrasias or coagulation defects and diabetes mellitus. There were also reports of an association between the development of SCH in the perioperative period with a history of liver disease and with preoperative use of digoxin ${ }^{(7)}$.

If an intraoperative $\mathrm{SCH}$ is suspected, immediate tamponade of the open globe is required. This can be accomplished by either direct digital pressure or rapid suturing of all surgical incisions. The long-term benefit of performing posterior sclerotomies immediately is doubtful. The creation of drainage sclerotomies in an experimental model, during the acute formation of $\mathrm{SCH}$, resulted in a further increase in the size of the $\mathrm{SCH}$ with marked extension of the hemorrhage into the retina and vitreous ${ }^{(19)}$. The mean clot lysis time for an $\mathrm{SCH}$ has been reported to be between 7 and 14 days. Attempts to drain an SCH before some degree of clot lysis has occurred are usually unsuccessful(1). Some recent reports have advocated early surgical
Funding: No specific financial support was available for this study.

Disclosure of potential conflicts of interest: F.Lavinsky, None; J.Moisseiev, None; H.Levkovitch-Verbin, None.

Corresponding author: Hani Levkovitch-Verbin. Goldschleger Eye Institute, Sheba Medical Center Tel-Hashomer, Israel, 52621 - E-mail: halevko@hotmail.com, hani.verbin@sheba.health.gov.il 
intervention in the management of $\mathrm{SCH}^{(20-22)}$. Despite all the surgical efforts, most studies report poor visual prognosis with a low final visual acuity at follow up ${ }^{(17,23,24)}$.

The indications and timing of drainage procedures in patients with a postoperative $\mathrm{SCH}$ depend on the ocular findings. These include the presence of retinal detachment, central retinal apposition ("kissing choroidals"), vitreous incarceration into the surgical wound, or a breakthrough vitreous hemorrhage; increased IOP; retained lens material during cataract surgery; and intractable eye pain. The surgical approach includes drainage through posterior sclerotomies, often in association with vitrectomy for removal of vitreous hemorrhage and/or retained lens material, and for reattaching detached retina ${ }^{(1)}$.

The present study describes the anatomic and functional results of drainage surgery in a consecutive series of cases with suprachoroidal hemorrhage.

\section{METHODS}

This is a cross-sectional retrospective study based on chart data from 9 eyes of 9 consecutive patients diagnosed with intraoperative or postoperative suprachoroidal hemorrhage ("expulsive hemorrhage") in our Institute between March 2002 and December 2007. The review of the charts was authorized by the hospital IRB. All patients had at least 4 month of follow up.

The data retrieved included demographic, ocular and systemic details of the patients prior to the procedure complicated by $\mathrm{SCH}$ (the primary procedure), following the $\mathrm{SCH}$ and prior to the second procedure (the drainage procedure), and throughout the follow up. Visual acuity (VA) was measured with Snellen chart, and the values were converted to logMAR for statistical analysis.

\section{RESULTS}

There were 3 females and 6 males, and the mean age was 74 years (range 61-84). The average follow-up time was $38.3 \pm 30.1$ months (range 4-87 months). Table 1 describes the demographic, systemic and ocular data of these patients. Three patients were taking aspirin when the SCH occurred, 6 patients had documented glaucoma and 3 patients had high myopia.
The primary procedures associated with the $\mathrm{SCH}$ are presented in table 1. There were four cases of glaucoma surgery (2 trabeculectomies and 2 Ahmed valve implantations), three cataract operations and two pars plana vitrectomies (PPV) for retinal detachment treatment. Intraoperative SCH occurred in the three cataract operations, and the other six cases had postoperative $\mathrm{SCH}$, within $6 \pm 3$ days (range 1 to 8 days) of the operation. On US examination there were kissing choroidals in 7 eyes. Retinal detachment was observed in 1 eye.

The surgical management of the $\mathrm{SCH}$ was performed $11 \pm 4$ days following the $\mathrm{SCH}$, as our policy is to wait at least 1 week prior to intervention, to allow for the liquefaction of the suprachoroidal blood. The procedure included: insertion of an anterior chamber maintainer (ACM) at the limbus for inducing the pressure required for the drainage and volume replacement, exposure of the sclera and bridle sutures for the extraocular muscles, and posterior drainage sclerotomies (beginning 5-8 mm posterior to the limbus and extending 3-5 mm posteriorly). The exact site of the sclerotomies was based on the US findings, corresponding to the locations where the $\mathrm{SCH}$ was thicker. PPV was performed in 6 of the 9 eyes at the same operation (Table 1), with silicone oil injection in five of these eyes. Additional procedures following the drainage procedures included removal of the silicone oil in 4 eyes (cases 4-6, 8), removal of the Ahmed valve (case 7), and reinsertion of the Ahmed valve tube to the anterior chamber (case 1). At the end of the follow up the retina was attached in all 9 eyes, and the silicone oil was retained in 2 eyes.

At one month of follow-up the visual acuity improved in 7 eyes and remained stable in 2, compared to the VA prior to the drainage operation (Table 2). The mean VA improved from 2.03 to 1.285 logMAR units at 1 month following the drainage procedure. In Snellen units, the VA improved from hand motions to 20/385. This corresponds to more than quadrupling of the visual angle $(p=0.003)$. In the 7 eyes that improved, the mean change was 1 logMAR unit, which is more than 10 lines of improvement. The VA slightly deteriorated at the end of the follow, to $1.441(20 / 552)(p=0.027)$.

\section{DISCUSSION}

In this study we present the results of a retrospective study that includes nine consecutive cases of intraoperative and postopera-

Table 1. Demographic and clinical characteristics

\begin{tabular}{|c|c|c|c|c|c|c|}
\hline $\begin{array}{l}\text { Patient. gender, } \\
\text { age, eye }\end{array}$ & $\begin{array}{l}\text { Systemic } \\
\text { conditions }\end{array}$ & $\begin{array}{l}\text { Ocular } \\
\text { pathology }\end{array}$ & $\begin{array}{l}\text { Primary } \\
\text { procedure }\end{array}$ & $\begin{array}{l}\text { Extent of } \\
\text { SCH by US }\end{array}$ & $\begin{array}{c}\mathrm{SCH} \\
\text { procedure }\end{array}$ & $\begin{array}{l}\text { Additional } \\
\text { procedures }\end{array}$ \\
\hline 1. $F, 77, L E$ & HTN, Hyperlipidemia & Glaucoma & $\begin{array}{l}\text { Ahmed valve } \\
\text { implant }\end{array}$ & Kissing & $\begin{array}{l}\text { SCD \& removal of } \\
\text { tube }\end{array}$ & $\begin{array}{l}\text { Reinsertion of tube } \\
\text { (8 mo later) }\end{array}$ \\
\hline 2. $M, 84, L E$ & None & BE glaucoma & Trabeculectomy & Kissing & SCD & None \\
\hline 3. $M, 74, L E$ & HTN, Aspirin & BE glaucoma, BE uveitis & Trabeculectomy & Non-kissing \& RD & SCD \& PPV \& SO & None \\
\hline 4. $M, 65, R E$ & HTN, IHD, Aspirin & None & PPV due to RD & Non-kissing & SCD \& PPV \& SO & $\begin{array}{l}\text { SO removal } \\
\quad(7 \mathrm{mo})\end{array}$ \\
\hline 5. F, 79, RE & CLL & $\begin{array}{c}\text { BE glaucoma, BE myopia, } \\
\text { BE advanced cataract }\end{array}$ & ICCE & Kissing & SCD \& PPV \& SO & $\begin{array}{l}\text { SO removal } \\
\text { (6 months) }\end{array}$ \\
\hline 6. $M, 81, R E$ & $\begin{array}{l}\text { IHD, sp CVA, } \\
\text { HTN, aspirin }\end{array}$ & None & $\mathrm{PHACO}+\mathrm{PCIOL}$ & Kissing & SCD \& PPV \& SO & $\begin{array}{l}\text { SO Removal } \\
\text { (9 months) }\end{array}$ \\
\hline 7. $M, 77, R E$ & HTN, IHD, DM, & BE glaucoma & $\begin{array}{l}\text { Ahmed valve } \\
\text { Implant }\end{array}$ & Kissing & SCD \& PPV & $\begin{array}{l}\text { Removal of the } \\
\text { Ahmed valve ( } 4 \text { months) }\end{array}$ \\
\hline 8. $M, 68, R E$ & None & BE glaucoma & $\begin{array}{c}\mathrm{ECCE}+\mathrm{ACIOL} \\
\text { with vitreous loss }\end{array}$ & Kissing & $\begin{array}{l}\mathrm{SCD} \& \mathrm{ACIOL} \\
\text { removal }\end{array}$ & $\begin{array}{l}\text { SO removal } \\
\text { ( } 2 \text { months) }\end{array}$ \\
\hline 9. F, 61, RE & None & $\begin{array}{l}\text { High myopia, aphakia, } \\
\text { retinal detachment }\end{array}$ & $\begin{array}{l}\text { PPV due to } \\
\text { RD recurrent }\end{array}$ & Kissing & SCD \& PPV \& SO & None \\
\hline
\end{tabular}

$\mathrm{F}=$ female; $\mathrm{M}=$ male; $\mathrm{LE}=$ left eye; $\mathrm{RE}=$ right eye; $\mathrm{HTN}=$ hypertension; $\mathrm{IHD}=$ ischemic heart disease; $\mathrm{DM}=$ diabetes mellitus; $\mathrm{SCH}=$ suprachoroidal haemorrhage; $\mathrm{SCD}=$ suprachoroidal haemorrhage drainage; $\mathrm{SO}=$ silicone oil; $\mathrm{PPV}=$ pars plana vitrectomy. 
Table 2. Visual acuity - in logMAR

\begin{tabular}{lccc}
\hline Patient & Prior to SCD & 1 month follow-up & Last follow-up (months) \\
\hline 1 & 2.2 & 0.8 & $2.0(87)$ \\
2 & 1.9 & 0.5 & $0.5(52)$ \\
3 & 2.2 & 1.3 & $1.6(4)$ \\
4 & 1.9 & 0.5 & $0.2(39)$ \\
5 & 2.2 & 1.7 & $1.7(22)$ \\
6 & 1.9 & 1.0 & $1.6(9)$ \\
7 & 1.9 & 2.0 & $1.4(66)$ \\
8 & 1.6 & 1.7 & $1.9(61)$ \\
9 & 2.5 & 2.0 & $2.2(5)$ \\
Average & 2.0 & 1.3 & $1.4(38.3)$ \\
\hline SCD & &
\end{tabular}

$\mathrm{SCD}=$ suprachoroidal hemorrhage drainage.

tive SCH in our department between 2002 and 2007. All patient included in this study had at least one systemic or ocular risk factor for developing $\mathrm{SCH}$. The more prevalent systemic risk factors were HTN and aspirin treatment, a finding that is in agreement with other studies ${ }^{(17,18,25)}$. Two well established ocular risk factors, glaucoma and myopia, were also common among our patients ${ }^{(17,26)}$.

Moshfeghi et al. published a case control study with 37 cases with SCH. Twenty-six cases (71\%) of SCH were related to a glaucoma operations. In a multivariate analysis they found that age, prior history of PPVx, and a history of glaucoma were each associated with a significantly greater risk of SCH ${ }^{(2)}$. In a British case-control study by Ling et al. the risk factors for developing $\mathrm{SCH}$ after cataract surgery included: older age $(p<0.001)$, taking at least one cardiovascular medication $(p<0.001)$, peripheral vascular disease $(p=0.014)$, hyperlipidemia ( $p=0.005)$, glaucoma $(p<0.001)$, elevated preoperative intraocular pressure $(p<0.001)$, sub-Tenon's local anaesthesia $(p<0.001)$, topical local anesthesia $(p<0.001)$, the lack of orbital compression following local anesthesia $(p<0.001)$, posterior capsule rupture before SCH $(p<0.001)$, elective extracapsular cataract extraction (ECCE) $(p=0.038)$, and phacoemulsification conversion $(p<0.001)^{(4)}$. In our study SCH occurred intraoperatively in the cataract cases, and postoperatively in the glaucoma and vitrectomy cases, most likely due to severe postoperative hypotony.

The best timing for the surgical drainage of the $\mathrm{SCH}$ is still undetermined. In our series the mean time from the occurrence of $\mathrm{SCH}$ to the drainage procedure was 11 days, similar to the report of Meier and Wiedermann - 11.3 days (range 6-20 days) $)^{(3)}$.

In our cases vitrectomy and silicone oil injection were performed in the majority of the cases, in order to prevent rebleeding or redetachment, and to maintain the vitreous space until the eye stabilizes.

Preservation of the globe and attached retina were achieved in all nine eyes. The VA improved significantly in seven eyes, but overall the final VA remained poor, except in one case (case 4) that improved dramatically. Wang et al. ${ }^{(17)}$ reported that after follow-up of 6 months, 12 eyes (30.77\%) had a final VA >4 / 200, and 12 eyes (30.77\%) measured no light perception (NLP), but they included cases of hemorrhagic $A M D$, that usually have very bad prognosis. Scott et al.(27) also reported poor visual prognosis after appositional SCH - only 15 (29.4\%) patients achieved either their prehemorrhage VA or 20/200 or better, and $14(27.5 \%)$ patients had no light perception. Feretis et al. published a case series of five patients with $\mathrm{SCH}$. All cases received medical therapy and underwent secondary surgical intervention with radial sclerotomies combined with vitrectomy, use of perfluorocarbon, and silicone oil. In all cases, anatomic restoration of ocular structures was achieved. The distance visual acuity improved in all cases ${ }^{(28)}$.

\section{CONCLUSION}

Suprachoroidal hemorrhage is a severe operative complication, and if left untreated is likely to result in phthysis and complete loss of all vision. Timely surgical management with drainage of the blood and often vitrectomy with silicone oil injection is indicated for restoring some vision and preserving the globe.

\section{REFERENCES}

1. Chu TG, Green RL. Suprachoroidal hemorrhage. Surv Ophthalmol. 1999;43(6):471-86

2. Moshfeghi DM, Kim BY, Kaiser PK, Sears JE, Smith SD. Appositional suprachoroidal hemorrhage: a case-control study. Am J Ophthalmol. 2004;138(6):959-63. Review.

3. Meier P, Wiedemann P. Massive suprachoroidal hemorrhage: secondary treatment and outcome. Graefes Arch Clin Exp Ophthalmol. 2000:238(1):28-32.

4. Ling R, Cole M, James C, Kamalarajah S, Foot B, Shaw S. Suprachoroidal haemorrhage complicating cataract surgery in the UK: epidemiology, clinical features, management, and outcomes. Br J Ophthalmol. 2004:88(4):478-80.

5. Davison JA. Acute intraoperative suprachoroidal hemorrhage in capsular bag phacoemulsification. J Cataract Refract Surg. 1993:19(4):534-7. Comment in J Cataract Refract Surg. 1993;19(6):813-4. J Cataract Refract Surg. 1993;19(6):814-5. J Cataract Refract Surg. 1994;20(1):106-8.

6. Eriksson A, Koranyi G, Seregard S, Philipson B. Risk of acute suprachoroidal hemorrhage with phacoemulsification. J Cataract Refract Surg. 1998;24(6):793-800.

7. Speaker MG, Guerriero PN, Met JA, Coad CT, Berger A, Marmor M. A case-control study of risk factors for intraoperative suprachoroidal expulsive hemorrhage. Ophthalmology. 1991;98(2):202-9; discussion 10.

8. Duncker Gl, Rochels R. Delayed suprachoroidal hemorrhage after penetrating keratoplasty. Int Ophthalmol. 1995;19(3):173-6.

9. Price FW Jr, Whitson WE, Ahad KA, Tavakkoli H. Suprachoroidal hemorrhage in penetrating keratoplasty. Ophthalmic Surg. 1994;25(8):521-5.

10. Purcell JJ Jr, Krachmer JH, Doughman DJ, Bourne WM. Expulsive hemorrhage in penetrating keratoplasty. Ophthalmology. 1982;89(1):41-3.

11. Givens K, Shields MB. Suprachoroidal hemorrhage after glaucoma filtering surgery. Am J Ophthalmol. 1987;103(5):689-94

12. Ruderman JM, Harbin TS Jr, Campbell DG. Postoperative suprachoroidal hemorrhage following filtration procedures. Arch Ophthalmol. 1986;104(2):201-5.

13. Ghoraba HH, Zayed Al. Suprachoroidal hemorrhage as a complication of vitrectomy. Ophthalmic Surg Lasers. 2001;32(4):281-8.

14. Lakhanpal V, Schocket SS, Elman MJ, Dogra MR. Intraoperative massive suprachoroidal hemorrhage during pars plana vitrectomy. Ophthalmology. 1990;97(9):1114-9.

15. Piper JG, Han DP, Abrams GW, Mieler WF. Perioperative choroidal hemorrhage at pars plana vitrectomy. A case-control study. Ophthalmology. 1993;100(5):699-704.

16. Beyer CF, Peyman GA, Hill JM. Expulsive choroidal hemorrhage in rabbits. A histopathologic study. Arch Ophthalmol. 1989;107(11):1648-53.

17. Wang LC, Yang CM, Yang CH, Huang JS, Ho TC, Lin CP, et al. Clinical characteristics and visual outcome of non-traumatic suprachoroidal haemorrhage in Taiwan. Acta Ophthalmol. 2008;86(8):908-12.

18. Cantor LB, Katz L, Spaeth GL. Complications of surgery in glaucoma. Suprachoroida expulsive hemorrhage in glaucoma patients undergoing intraocular surgery. Ophthalmology. 1985;92(9):1266-70.

19. Lakhanpal V. Experimental and clinical observations on massive suprachoroidal hemorrhage. Trans Am Ophthalmol Soc. 1993:91:545-652.

20. Abrams GW, Thomas MA, Williams GA, Burton TC. Management of postoperative suprachoroidal hemorrhage with continuous-infusion air pump. Arch Ophthalmol. 1986;104(10):1455-8.

21. Ariano ML, Ball SF. Delayed nonexpulsive suprachoroidal hemorrhage after trabeculectomy. Ophthalmic Surg. 1987;18(9):661-6.

22. Gressel MG, Parrish RK 2nd, Heuer DK. Delayed nonexpulsive suprachoroidal hemorrhage. Arch Ophthalmol. 1984;102(12):1757-60.

23. Lakhanpal V, Schocket SS, Elman MJ, Nirankari VS. A new modified vitreoretina surgical approach in the management of massive suprachoroidal hemorrhage. Ophthalmology. 1989;96(6):793-800. Comment in Ophthalmology. 1990;97(2):149.

24. Lambrou FH Jr, Meredith TA, Kaplan HJ. Secondary surgical management of expulsive choroidal hemorrhage. Arch Ophthalmol. 1987;105(9):1195-8.

25. Tabandeh H, Sullivan PM, Smahliuk P, Flynn HW Jr, Schiffman J. Suprachoroidal hemorrhage during pars plana vitrectomy. Risk factors and outcomes. Ophthalmology. 1999;106(2):236-42.

26. Chak M, Williamson TH. Spontaneous suprachoroidal haemorrhage associated with high myopia and aspirin. Eye (Lond). 2003;17(4):525-7.

27. Scott IU, Flynn HW Jr, Schiffman J, Smiddy WE, Murray TG, Ehlies F. Visual acuity outcomes among patients with appositional suprachoroidal hemorrhage. Ophthalmology. 1997;104(12):2039-46. Erratum in: Ophthalmology 1998;105(3):394

28. Feretis E, Mourtzoukos S, Mangouritsas G, Kabanarou SA, Inoba K, Xirou T. Secondary management and outcome of massive suprachoroidal hemorrhage. Eur J Ophthalmol. 2006;16(6):835-40. 